\title{
Os três momentos pedagógicos na Educação Infantil: experiências práticas de Educação Ambiental
}

\author{
Los tres momentos pedagógicos en la Educación Infantil: experiencias \\ prácticas de Educación Ambiental
}
The three pedagogical moments in Early Childhood Education: practical experiences of Environmental Education

Lia Heberlê de Almeida ${ }^{1}$

\begin{abstract}
Resumo
Este texto tem como objetivo investigar a importância do ensino de Ciências Naturais na Educação Infantil, a partir do relato de uma experiência didática. Para a realização deste trabalho recorreu-se a pesquisas bibliográficas e estudo de caso, onde foram realizadas análises nas ações do projeto "Educação Ambiental: primeiros passos na educação infantil" em duas turmas de Pré-Escola (Pré B) na Escola Municipal de Educação Infantil Nossa Senhora Menina, do município de São Gabriel/RS. A metodologia foi organizada nos três momentos pedagógicos de Delizoicov e Angotti (1991), para desenvolvimento das atividades com alunos, e aplicação de questionários com os pais. Trata-se de uma investigação com caráter qualitativo, caracterizando-se como uma pesquisa participante.
\end{abstract}

Palavras-chave: Educação Ambiental; Educação Infantil; Reciclagem.

\section{Resumen}

Este texto de interés para investigar la importancia de la enseñanza de las Ciencias Naturales en la escuela primaria de la niñez, basada en el informe de la didactic experience. En el caso de que se trate de llevar a cabo este trabajo, se utilizó una bibliografía bibliográfica y un estudio de casos, donde se realizaron en las acciones del proyecto "Educación para la Educación: primeros pasos en una escuela de educación temprana" en la Municipalidad de Educación Infantil Nuestra Señora Chica, desde la sede de San Gabriel / RS. La metodología fue organizado en los tres momentos pedagógicos de Delizoicov y Angotti (1991) para el desarrollo de actividades con los estudiantes, y la aplicación de cuestionarios con los padres. Esta es una investigación con un carácter cualitativo, caracterizando a las participantes.

Palabras clave: Educación Ambiental. Educación Infantil. Reciclaje.

\begin{abstract}
This text aims to investigate the importance of the teaching of Natural Sciences in Early Childhood Education, based on the report of a didactic experience. In order to carry out this work, we used bibliographical research and a case study, where analyzes were carried out in the actions of the project "Environmental Education: first steps in early childhood education" in two classes of Pre-School (Pre B) in the Municipal School of Education InfantilNossaSenhoraMenina, from the municipality of São Gabriel / RS. The methodology was organized in the three pedagogical moments of Delizoicov and Angotti (1991), for the development of activities with students, and the application of questionnaires with parents. This is a research with a qualitative character, characterizing itself as a participant research.
\end{abstract}

\footnotetext{
${ }^{1}$ Mestra em Educação em Ciências pela Universidade Federal do Rio Grande do Sul ,UFRGS, Porto Alegre, Rio Grande do Sul. E-mail: lia_ha@hotmail.com
} 
Keywords: Environmental education; Child education; Recycling.

\title{
1. Introdução
}

O ensino de Ciências, nas diferentes etapas da Educação Básica, tem como objetivo principal potencializar a formação cidadã, onde o estudante seja capaz de atuar criticamente, agindo com responsabilidade na tomada de decisões. Desta forma, os conceitos de alfabetização científica e letramento em Ciências tornam-se pertinentes para debate na Educação Infantil.

\begin{abstract}
A categoria letramento em Ciências refere-se à forma como as pessoas utilizarão os conhecimentos científicos, seja no seu trabalho ou na vida pessoal e social, melhorando a sua vida ou auxiliando na tomada de decisões frente a um mundo em constante mudança. [...] Portanto, a alfabetização científica no ensino de Ciências Naturais nas séries iniciais é aqui compreendida como um processo pelo qual a linguagem das ciências adquire significados, constituindo um meio para o indivíduo ampliar seu universo de conhecimento, a sua cultura, como cidadão inserido na sociedade (LORENZETTI; DELIZOICOV, 2001, p.8).
\end{abstract}

A abordagem do professor deve propiciar momentos de diálogo crítico e reflexivo, ações planejadas, saídas a campo, dentre outras estratégias que proporcionem aos alunos oportunidades de observar os fenômenos naturais, o ambiente que os cerca e os resultados gerados pela intervenção humana.

Neste sentido, no contexto do município de São Gabriel/RS, há uma necessidade urgente de medidas para minimizar alguns problemas referentes às questões que envolvem o lixo e na intenção de contribuir com a coleta seletiva deste município. No primeiro semestre do ano letivo de 2018, em duas turmas de Educação Infantil (turmas de Pré B), propôs-se o projeto "Educação ambiental: primeiros passos na educação infantil", que abrangeu cerca de 40 alunos.

Nesta ação, os estudantes participaram de atividades e de aulas de campo que envolvia as temáticas de reciclagem de óleo de cozinha, lixo eletrônico e lixo doméstico, ou seja, conceitos que avançam para o desenvolvimento da consciência ambiental. Os estudantes fizeram campanhas junto a seus familiares para coleta de materiais. Estas atividades foram 
propostas como forma de conscientização acerca da importância do papel cidadão de cada pessoa na sociedade.

A coleta seletiva é uma alternativa ecologicamente correta que esta em processo inicial neste município, sendo um sistema de recolhimento de materiais recicláveis, previamente separados na fonte geradora. Da mesma forma, estão sendo implantadas, através da Secretaria Municipal de Educação, ações para a coleta de óleo de cozinha e lixo eletrônico. Assim, ratifica-se a importância de educar a comunidade escolar para o conhecimento sobre estas estratégias e sensibilizar os estudantes para participar.

Deste modo, a abordagem desta temática na Educação Infantil torna-se relevante pela necessidade de iniciar na infância o processo de Educação Ambiental. Visto que as crianças são agentes de transformação na sociedade e através de atividades escolares elas podem colaborar para a mudança de hábitos e atitudes em suas residências, na medida em que são sensibilizados sobre os problemas do desperdício de recursos naturais e da poluição causada pelo lixo.

Neste sentido, este artigo tem como objetivo investigar a importância do ensino de Ciências Naturais na Educação Infantil. Para este fim, relata-se a experiência didática de um projeto de educação ambiental realizado em duas turmas de Pré B. Subsidiam este relato os seguintes referenciais: LORENZETTI; DELIZOICOV (2001); TREVISAN, FORSBERG (2014); DELIZOICOV; ANGOTTI (1992); MOLL, J. (2004); entre outros.

O texto está organizado em quatro partes: um breve panorama do estudo na introdução; exposição sobre os pressupostos teóricos; metodologia utilizada para a realização das atividades; e finaliza com os resultados e seus desdobramentos nas considerações finais e suas implicações para o ensino de Ciências na Educação Infantil.

\section{Metodologia}

Esta pesquisa almeja contribuir para a formação cidadã, o pensamento crítico e reflexivo, bem como o reconhecimento do estudante como agente transformador de sua realidade. Desta forma, a participação dos sujeitos tornou-se o principal pilar metodológico, caracterizando esta pesquisa com uma abordagem metodológica qualitativa de natureza interpretativa com observação participante.

A Pesquisa Participante possui uma vinculação histórica com projetos de transformação social emancipatória e as bases de suas propostas são pautadas por uma 
construção dialógica, partindo da premissa que conhecer o mundo é fundamental para transformá-lo (BRANDÃO e STRECK, 2006).

A pesquisa foi realizada com 40 alunos, de duas turmas de Educação Infantil (Pré B), da Escola Municipal de Educação Infantil Nossa Senhora Menina do município de São Gabriel. Estes estudantes, com idades entre de 5 a 6 anos, participaram das atividades do projeto no período de março a julho de 2018.

Neste sentido, é importante destacar que o ensino de ciências é reconhecido por pesquisadores pela sua importância aos alunos, como afirma Delizoicov, Angotti e Pernambuco (2011) que "parece claro que uma das funções do ensino de Ciências nas escolas fundamental e média é permitir ao aluno se apropriar da estrutura do conhecimento científico e de seu potencial explicativo e transformador."

$\mathrm{Na}$ Educação Infantil, o professor necessita de um conjunto de habilidades e competências que atendam as necessidades básicas do estudante. Isso, desde a afetividade, passando pela rigorosidade de compreender os estágios de desenvolvimento, sem avançar para conteúdos do ensino fundamental, respeitando a sua maturidade e ainda promover, de forma lúdica, uma abordagem de ensino que envolva o estudante e que o faça compreender o seu papel enquanto sujeito em uma sociedade.

Desta forma, procurou-se adaptar a metodologia dos Três Momentos Pedagógicos de (DELIZOICOV e ANGOTTI, 1992) para a estruturação e desenvolvimento deste trabalho, que organiza o planejamento em: Problematização Inicial (PI), Organização do Conhecimento (OC) e Aplicação do Conhecimento (AC).

Problematização Inicial (PI): deve partir do princípio que a "problematização é fazer com que o aluno sinta a necessidade da aquisição de outros conhecimentos que ainda não detém, ou seja, procura-se configurar a situação em discussão como um problema que precisa ser enfrentado." (DELIZOICOV, 2005, p.12).

Organização do Conhecimento (OC): neste momento o professor irá fazer a seleção dos conteúdos e conceitos a serem estudados, aprofundados e discutidos por meio de diferentes atividades, de forma que as problematizações e questões discutidas na Problematização Inicial possam ser respondidas e o aluno possa se apropriar do conhecimento. (DELIZOICOV, 2005).

Aplicação do Conhecimento (AC): momento destinado a sistematização do conhecimento construído pelo aluno, para analisar e interpretar tanto as situações ligadas a temática inicial de estudo, quanto as suas influências externas. (DELIZOICOV, 2005). 
Além disso, esta pesquisa contou com a participação de 20 pais $^{2}$ dos alunos participantes do projeto. O instrumento pelo qual realizou-se a coleta de dados foi os questionários e este estruturado com perguntas fechadas, que teve como objetivo identificar a efetivação do trabalho de educação ambiental realizado com os estudantes.

\section{Saídas de Campo: recurso educativo presente no território urbano}

O ensino de Ciências e a formação para cidadania são pertinentes na Educação Infantil, visto que as crianças estão na fase do desenvolvimento infantil Pré-Operatório (2 a 7 anos), uma fase permeada de descobertas e encantamento. As crianças são espontaneamente curiosas, investigativas e observadoras, demonstram bastante interesse em conhecer e compreender o mundo (PIAGET, 1990). O professor como mediador da aprendizagem desenvolverá um importante papel de motivar, provocar e instigar os estudantes nesta fase, usufruindo e direcionando estas competências para a construção de conhecimento e percepção da realidade.

Nesse sentido, a reflexão sobre as potencialidades do trabalho de campo torna-se relevante, uma vez que, aproveitando dos recursos disponíveis no território urbano, possibilita o aprendizado nas múltiplas dimensões, o resgate da imaginação e do encantamento, considerando as dimensões sócio-histórico e cultural dos sujeitos.

Além disso, destacamos o caráter interdisciplinar das saídas a campo, que proporciona aos estudantes a aprendizagem fora do contexto escolar, explorando diversos espaços da cidade e suas possibilidades formativas compreendendo-a assim como um grande território educativo.

O trabalho de campo propicia experiências únicas e carrega significado no planejamento do professor e na construção da aprendizagem dos estudantes. Através do trabalho de campo o aluno tem a possibilidade de relacionar conhecimentos com a prática e o momento que deixa de ser espectador e passa a ser protagonista de sua aprendizagem.

Figueiredo e Silva (2009) confirmam, "a aula de campo surge com um novo sentido onde o aluno agora não é apenas um observador, mas um investigador que procura ser parte integrante da paisagem". Da mesma forma, se alinha com o pensamento de Freire (2002) sobre a articulação de conhecimentos, onde os saberes coletivos são interligados ao saber popular, crítico e científico, na relação com o mundo.

\footnotetext{
${ }^{2}$ Os pais dos estudantes foram escolhidos aleatoriamente, sendo aplicado com aqueles que tiveram interesse em responder a pesquisa e estavam presentes no dia de sua aplicação.
} 
Os espaços visitados e explorados passam a ter uma compreensão diferente, oferecendo novas formas de pensar e fazer ciência, influenciando diretamente no seu modo de agir e enxergar o mundo a sua volta. Essas vivências despertam no aluno uma consciência crítica sobre suas ações, e o reconhecimento do estudante como integrante deste movimento é um dos pilares para a construção de cidadania.

\section{A temática do lixo na Educação Infantil}

O tema lixo foi introduzido no trabalho pedagógico de forma a problematizar a realidade vivenciada no município de São Gabriel/RS. A temática foi definida considerando a necessidade de trabalhar com o meio ambiente e com a área do conhecimento das Ciências da Natureza na etapa da Educação Infantil.

O projeto foi fragmentado em três temáticas de reciclagem, dividido em: reciclagem do óleo de cozinha, reciclagem de lixo eletrônico e reciclagem de lixo doméstico.

\section{A Problematização Inicial}

A Problematização Inicial, das três estruturas deste projeto, ocorreu através de rodinha de conversa. Iniciou-se com o tema reciclagem do óleo de cozinha que foi introduzido através da hora do conto com a história "O mundinho azul". Neste livro, a autora Ingrid Biesemeyer Bellinghausen, de uma forma divertida expõe a importância da água e a necessidade de preservá-la.

Nesse sentido, a professora fez alguns questionamentos aos alunos e outros foram surgindo naturalmente durante a rodinha, mediada pela professora, tais como: A água é importante? Para que precisamos da água? Por que precisamos cuidar da água? Como podemos cuidar da água? A mamãe faz alimentos fritos em casa? E o óleo usado para fritar estes alimentos onde é descartado?

A segunda temática deste projeto refere-se à reciclagem de lixo eletrônico, com o intuito de identificar os objetos tecnológicos presentes no cotidiano dos estudantes e o destino dado a estes objetos quando não têm mais utilidade em sua casa. Para essa atividade foram oferecidos panfletos que continham eletroelotrônicos de lojas de da cidade, onde eles puderam observar uma variedade de produtos. 
Os alunos demonstraram interesse por alguns produtos e começaram a identificar os produtos que tinham em suas residências. Em seguida, foram questionados, ainda na rodinha de conversa sobre: Se você pudesse comprar um produto, qual produto você escolheria? E o que faria com o antigo de sua casa?

$\mathrm{Na}$ abordagem sobre a reciclagem de lixo doméstico a problematização ocorreu com a hora do conto, com a história "Família urso e a reciclagem de plástico". Neste livro, a autora Tatiany Telles Renó, utiliza-se de uma estrutura diferenciada, na qual em algumas páginas observa-se apenas a presença de texto e outras somente imagens, onde a criança é desafiada a criar e dar continuidade a história junto com a autora. Este livro trata sobre a reciclagem do lixo, coleta seletiva e lixeiras seletivas.

Desta forma, ainda na rodinha os alunos foram questionados: O que devemos fazer com as garrafas pet? As lixeiras têm diferenças? Que diferenças são estas? O que é reciclagem de lixo? Por que é importante separarmos o lixo?

Neste sentido, cabe ressaltar a importância da rodinha de conversa na Educação Infantil para a aprendizagem, desenvolvimento e relações sociais das crianças com seus pares e com a professora, ratificada pelas Diretrizes Curriculares Nacionais para a Educação Infantil em sua descrição, como

[...] o momento privilegiado de diálogo e intercâmbio de ideias. Por meio desse exercício cotidiano as crianças podem ampliar suas capacidades comunicativas, como a fluência para falar, perguntar, expor suas ideias, dúvidas e descobertas, ampliar seu vocabulário e aprender a valorizar o grupo como instância de troca e aprendizagem. A participação na roda permite que as crianças aprendam a olhar e a ouvir os amigos, trocando experiências (BRASIL, 1998, v. 3, p. 138).

Além disso, a utilização do diálogo como forma de provocar, instigar e problematizar são meios de envolver e contextualizar o estudante com a temática em estudo, nas questões a serem resolvidas e, na tomada de decisões e atitudes sobre o assunto. Como afirma Freire (2002, p. 78),

O diálogo-problematizador é o conceito central da educação libertadora freireana. É o encontro das pessoas através da palavra, pois "não é no silêncio que os homens se fazem, mas na palavra, no trabalho, na ação-reflexão".

Neste momento, os alunos são encorajados a participar do processo, através da fala e a oportunidade de expressar suas opiniões e a sua forma de ver o mundo. Manifestando suas ideias, escutando e respeitando o outro, as crianças democraticamente vão experimentando a 
construção coletiva de conhecimento, direcionando formas para a resolução de questões que surgem no grupo.

\title{
6. Organização do Conhecimento
}

O desenvolvimento desta etapa para as três temáticas deste estudo foi através da utilização de vídeos ${ }^{3}$ educativos e atividades impressas, considerando a faixa etária dos estudantes e as potencialidades desta ferramenta no processo de aprendizagem. Moran (1993, p 2) conceitua sobre a utilização do vídeo,

\begin{abstract}
Sensorial, visual, linguagem falada, linguagem musical e escrita. Linguagens que interagem superpostas, interligadas, somadas, não separadas. Daí a sua força. Nos atingem por todos os sentidos e de todas as maneiras. O vídeo nos seduz, informa, entretém, projeta em outras realidades (no imaginário) em outros tempos e espaços. O vídeo combina a comunicação sensorial-cinética com a audiovisual, a intuição com a lógica, a emoção com a razão. Combina, mas começa pelo sensorial, pelo emocional e pelo intuitivo, para atingir posteriormente o racional. (MORAN, 1993, p.2)
\end{abstract}

Porém, a mediação do professor para utilização deste recurso é fundamental, ainda que ele seja permeado de diferentes estímulos e informações. Nenhuma tecnologia é estanque a ponto de desconsiderar as intervenções do professor. $\mathrm{O}$ professor enquanto mediador do conhecimento utilizará deste recurso como subsídio em suas aulas, com muito critério, desde a escolha até o momento da execução.

É importante destacar que no Artigo $9^{\circ}$ das Diretrizes Curriculares Nacionais para a Educação Infantil ratifica que as práticas pedagógicas, devem ter como "eixos norteadores as interações e a brincadeira", garantindo experiências que "possibilitem a utilização de gravadores, projetores, computadores, máquinas fotográficas, e outros recursos tecnológicos e midiáticos." (BRASIL, 2009, p.4).

\section{Aplicação do Conhecimento}

A última etapa deste projeto para as três temáticas foi efetuada através das saídas a campo. Os Parâmetros Curriculares Nacionais de Ciências Naturais (1998) apontam aspectos

\footnotetext{
${ }^{3}$ Breve descrição das estruturas e vídeos utilizados para cada uma delas: 1 - Reciclagem de óleo de cozinha Vídeo: Um Plano para Salvar o Planeta (Especial de férias 2011) | Turma da Mônica. Disponível em: https://youtu.be/L3zaoUaHJhQ. 2 - Reciclagem de lixo eletrônico - Vídeo: Lixo Eletrônico - Qual o melhor destino para ele? Disponível em: https://youtu.be/Yo7obqWfMmU. 3 - Reciclagem de lixo doméstico - Vídeo: Um plano para salvar o planeta. Disponível em: https://youtu.be/JXHKKiaD-ks.
} 
relevantes a serem considerados nos trabalhos de campo, estimulando sua realização, sendo que "Atualmente é impensável o desenvolvimento de ensino de Ciências de qualidade sem o planejamento de trabalhos de campo que sejam articulados aos trabalhos de classe" (BRASIL, 1998, p. 126).

A reciclagem de óleo de cozinha no município de São Gabriel-RS ocorre através dos Ecopontos ${ }^{4}$, localizados na empresa responsável pelo saneamento básico e em algumas escolas públicas. O desenvolvimento desta etapa aconteceu através da coleta que os estudantes fizeram em suas residências, juntamente com seus familiares.

Com o objetivo de ampliar os conhecimentos dos alunos em relação ao assunto, foi realizada visitação em dois Ecopontos para entregar o óleo de cozinha coletado.

Figura 1 - Entrega de óleo de cozinha na empresa de saneamento básico e na escola pública.
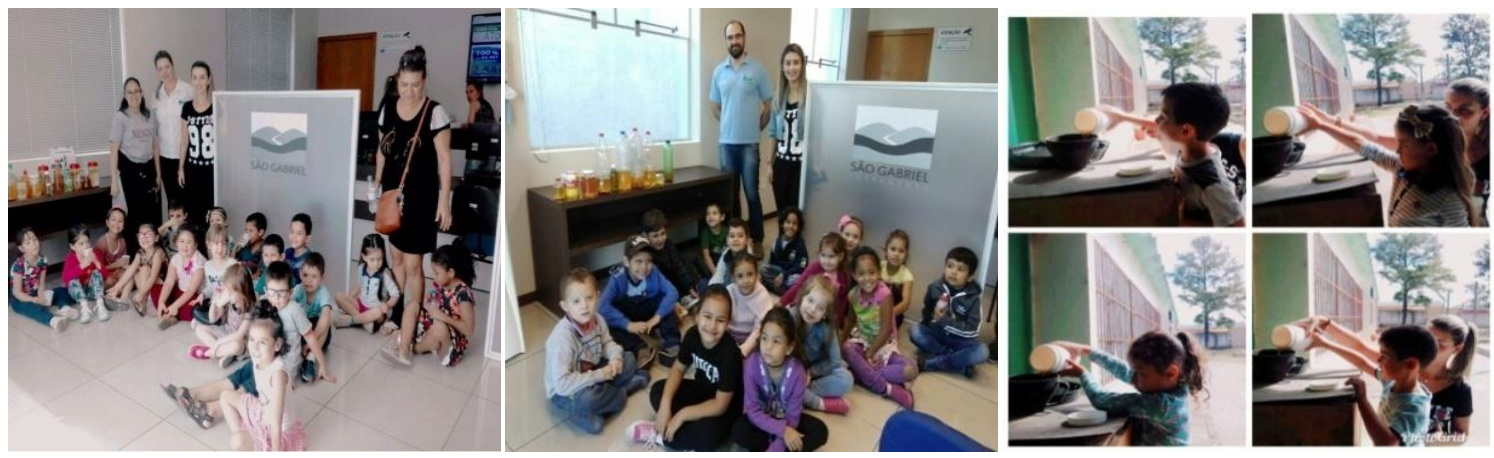

Fonte: Trabalho de Campo (2018)

A abordagem sobre a temática do lixo eletrônico ocorreu com a exploração do tema em sala de aula, pela professora, o qual foi solicitado aos alunos que, junto com suas famílias, arrecadassem objetos tecnológicos para levarmos para reciclagem. O resultado foi muito positivo, visto que foi recebida uma quantidade significativa de materiais.

Figura 2 - Entrega dos objetos tecnológicos no ECOPONTO.

\footnotetext{
${ }^{4}$ Os ecopontos são locais de entrega voluntária de pequenos volumes de entulho (até $1 \mathrm{~m}^{3}$ ), grandes objetos (móveis, restos de poda de árvores, entre outros) e resíduos recicláveis. (SECOVI, 2013).
} 

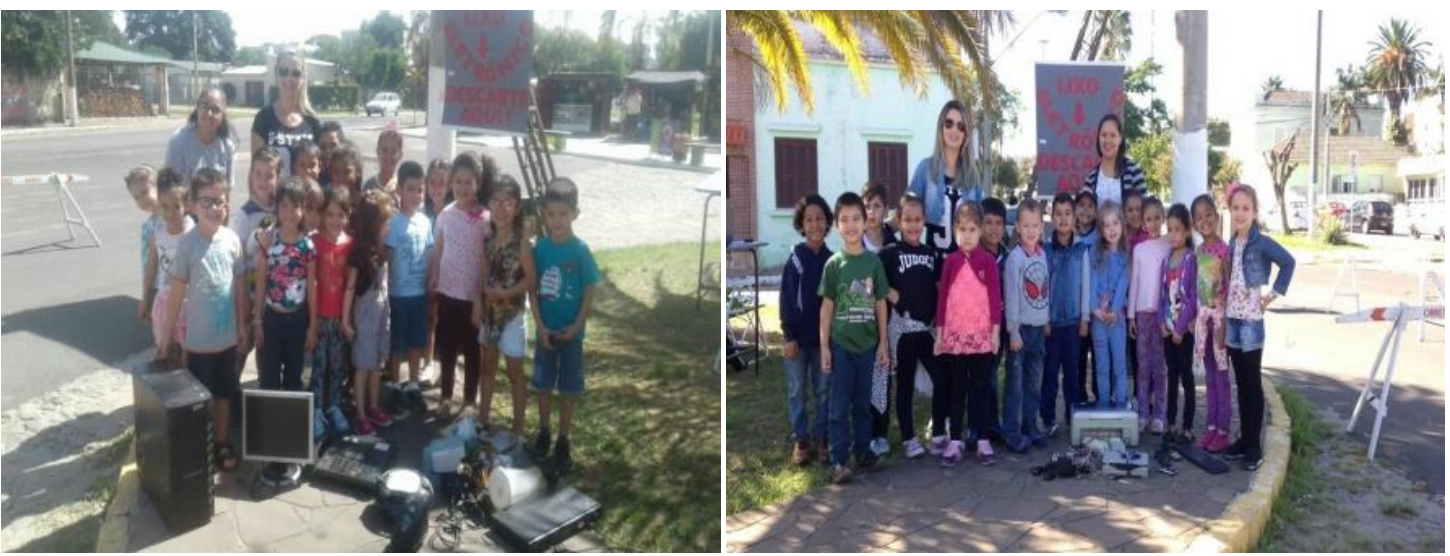

Fonte: Trabalho de Campo (2018)

A aplicação do conhecimento para a temática do lixo doméstico realizou-se através de um passeio ao arredor da escola. Durante o passeio os alunos usaram aventais com as cores das lixeiras seletivas e objetivava coletar lixo que estava em locais inapropriados.

Ao retornar para a sala de aula foi feita uma conversa sobre as lixeiras comuns e lixeiras seletivas. Após, cada aluno separou os resíduos encontrados no passeio, nas respectivas lixeiras com cores correspondentes ao tipo de material e foi problematizado o contexto do tempo de decomposição dos resíduos, através do vídeo "Tempo de Decomposição dos Resíduos"

Figura 3 - Coleta de lixo nas áreas ao redor da escola e classificação em sala de aula.
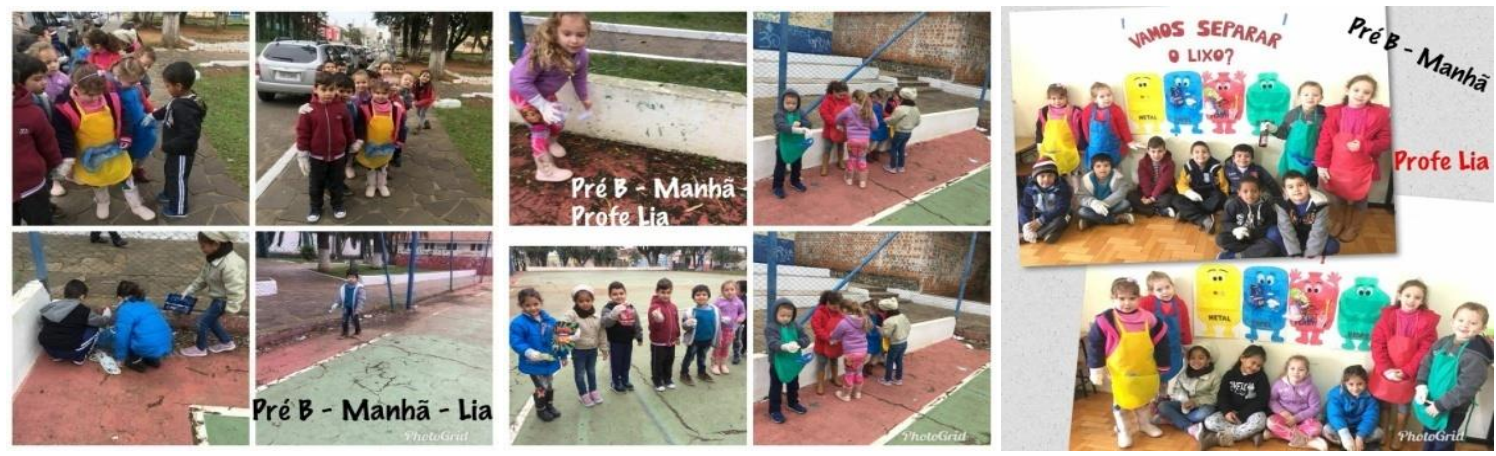

Fonte: Trabalho de Campo (2018)

Neste sentido, é importante ressaltar a relevância das aulas de campo em Ciências, pois

\footnotetext{
${ }^{5}$ Disponível em: https://youtu.be/1kKFFmNrcgk
} 
[...] proporciona um olhar crítico sobre a realidade associado a um ensino prazeroso e contextualizado[...] Em segundo, por considerar que a aula de campo possibilita ao educador adotar novos/outros procedimentos metodológicos e cognitivos, no qual intencionalmente possibilita a imersão do estudante a novas situações de aprendizagem, viabilizando a sensibilização e construção de uma postura que convirja para um posicionamento crítico e de responsabilidade social frente às situações presenciadas. (TREVISAN, FORSBERG, 2014, p.139).

Além disso, as saídas a campo garantem maiores oportunidades para a construção de conhecimento devido a diversos recursos naturais e culturais disponíveis fora da escola. Além disso, oferece diferentes abordagens de um mesmo tema e possibilita manter, construir e ampliar diálogos entre alunos, professores, pais, comunidade, por intermédio da expansão do território educativo.

Sobretudo, este debate está ambientado nos pressupostos das Cidades Educadoras, que se iniciou nos anos 90, e compreende a cidade e seu entorno, como locais ricos e dinâmicos que oferecem inúmeras possibilidades de convivência e cidadania.

Moll (2004, p.42) afirma que a educação na perspectiva das cidades educadoras pressupõe

[...] a compreensão da cidade com uma grande rede ou malha de espaços pedagógicos formais (escolas, creches, faculdades, universidades, institutos) e informais (teatros, praças, museus, bibliotecas, meios de comunicação, repartições públicas, igrejas, além do trânsito, do ônibus, da rua) que, pela intencionalidade das ações desenvolvidas, pode converter a cidade em território educativo, pode fazer da cidade uma pedagogia (MOLL, 2004, p.42)

Assim sendo, ao envolver as pessoas com as questões do espaço em que elas vivem, criam-se estruturas nas quais os pais das crianças participam, constitui-se um movimento de aldeia, onde a construção de conhecimento acontece dos adultos para as crianças e das crianças para os adultos. Observa-se assim a importância do professor em estimular estas práticas e fortalecer as estratégias adotadas pela cidade na construção de estruturas de participação da população para uma educação cidadã.

\section{Os reflexos e desdobramentos da pesquisa}

Conforme descrito na metodologia, foi aplicado um questionário estruturado para 20 pais de alunos participantes do projeto, que forneceu dados importantes a serem discutidos. Os entrevistados foram questionados sobre o conhecimento e utilização dos Ecopontos, bem como suas impressões sobre a participação dos estudantes no projeto. 
No que se refere ao conhecimento dos Ecopontos de óleo de cozinha e lixo eletrônico, $70 \%$ não sabiam da existência do local para descarte de óleo de cozinha e 55\% também não conheciam o Ecoponto de lixo eletrônico.

Observa-se que a problemática ambiental está presente no nosso cotidiano. Ao abrirmos o jornal, ao assistirmos o noticiário na TV, ao analisar o feed de notificações das redes sociais e tantos outros meios de comunicação, nos deparamos com algo referente a problemas ambientais e isso reforça a necessidade de intensificar a informação e a educação para a população.

Porém, campanhas e divulgações por si só, não minimizam esta problemática. A educação para cidadania e a discussão sobre os impactos ambientais e sociais, das atitudes de cada pessoa são imprescindíveis para viabilização da Educação Ambiental.

Chama a atenção que $80 \%$ dos entrevistados nunca utilizaram do Ecoponto de óleo de cozinha e $75 \%$ não possuem o hábito de utilizar do Ecoponto de lixo eletrônico. Estes dados mostram que mesmo aqueles que sabem da existência dos Ecopontos, nunca utilizaram destes mecanismos de reciclagem, o que ratifica a emergência de conhecimento sobre as questões ambientais.

A ABRELPE (Associação Brasileira de Empresas de Limpeza Pública) identificou em uma de suas pesquisas, que entre o ano de 2016 e 2017, houve um aumento de $3 \%$ do despejo inadequado de lixo no Brasil. Desta forma, podemos perceber a amplitude da crise ambiental e as inúmeras questões que podem estar envolvidas, pois mesmo vivendo em um mundo permeado de descobertas científicas, de inovações tecnológicas e de ampla discussão sobre Educação Ambiental, os índices continuam desfavoráveis.

Fracalanza, Amaral, Neto e Eberlin (2005, p.13) apontam que: "De fato, as concepções de Educação Ambiental são diversas e variadas, pois dependem das concepções que seus participantes tem de Educação, de Ambiente e de Sociedade.” Várias vertentes de Educação Ambiental existem, mas percebemos um longo caminho ainda a ser trilhado, considerando que $91,24 \%$ das cidades brasileiras possuem coleta de lixo, mas apenas 59,1\% possuem descarte correto do lixo (ABRELPE, 2018).

Porém, pequenas iniciativas para minimizar os problemas ambientais são ferramentas valiosas para o meio ambiente, bem como mostram as entrevistas: os pais quando questionados se os seus filhos apresentaram mudanças de atitudes em casa, após a realização do projeto, $100 \%$ confirmaram a mudança e, ao serem questionados, se pretendem utilizar os Ecopontos de lixo eletrônico e óleo de cozinha, $100 \%$ manifestam o desejo de utilizar. 
A partir destes dados acredita-se que a participação destes alunos no projeto, provocou mudanças de atitudes e momentos de reflexão sobre hábitos cotidianos, pois foram unânimes em relatar que pretendem utilizar dos Ecopontos. Essa amostra e essas conclusões enfatizam a relevância do desenvolvimento de Projeto de Educação Ambiental, podendo iniciar-se na Educação Infantil.

\section{Considerações Finais}

Neste artigo, apresentamos o resultado de um estudo que teve como propósito investigar a importância do ensino de Ciências Naturais na Educação Infantil, a partir do desenvolvimento do projeto sobre Educação Ambiental, com duas turmas de Pré-Escola (PréB) da EMEI Nossa Senhora Menina. Este estudo foi dividido em três blocos temáticos: reciclagem de óleo de cozinha, reciclagem de lixo eletrônico e reciclagem de lixo doméstico, proporcionando aos alunos reflexões e vivências sobre estes conceitos

O projeto desenvolvido com os alunos, que deu origem a este artigo, propiciou momentos de diálogo-crítico e reflexivo, através de rodinhas de conversas e a partir destes debates constituíram-se ações práticas em sala de aula e saídas a campo, promovendo uma conscientização para reciclagem.

O trabalho com os vídeos em sala de aula favoreceu a compreensão dos estudantes e a problematização das temáticas. A abordagem do tema aconteceu de uma forma lúdica e divertida em desenho animado, facilitando a compreensão e apropriação do conhecimento pelos estudantes, por envolvê-los com o tema utilizando de uma linguagem própria com a sua faixa-etária.

O momento de culminância das atividades, com a aplicação do conhecimento, foi extremamente significativo, pois possibilitou os estudantes conhecerem os Ecopontos do município, e assim puderam perceber as ações que a cidade realiza, em prol da reciclagem, aproximando a realidade fora dos muros da escola, com a vivência destes estudantes.

Desta forma, Lorenzetti eDelizoicov (2001, p. 53) afirmam que os "espaços e meios que podem auxiliar na complexa tarefa de possibilitar a compreensão do mundo" e salienta a importância da atuação docente em sua especificidade, para condução, planejamento e execução do trabalho, sugerindo algumas estratégias para o ensino de ciências.

Dentre outras atividades possíveis de serem desenvolvidas destacamos as seguintes: o uso sistemático da literatura infantil, da música, do teatro e de vídeos educativos, reforçando a necessidade de que o professor pode, através de escolha apropriada, ir 
trabalhando os significados da conceituação científica veiculada pelos discursos contidos nestes meios de comunicação; explorar didaticamente artigos e demais seções da revista Ciência hoje das Crianças, articulando-os com aulas práticas; visitas a museus; zoológicos, industrias, estações de tratamento de águas e demais órgãos públicos; organização e participação em saídas a campo e feiras de Ciências; uso do computador da Internet no ambiente escolar. (LORENZETTI; DELIZOICOV, 2001, p.53)

Assim, observa-se que as práticas aplicadas neste projeto dialogam com a proposta de Lorenzetti e Delizoicov (2001). Pode-se considerar que os objetivos propostos foram atingidos ao observar a participação dos alunos para a coleta de materiais para reciclagem e o envolvimento com as atividades, bem como pelos relatos dos pais no questionário em sua totalidade apontando mudanças de comportamentos nos hábitos diários das crianças sobre a reciclagem e mostrando interesse em utilizar dos Ecopontos.

Portanto, percebe-se que o horizonte do debate de educação ambiental deve ter como finalidade orientar ações oportunizando um ensino com relevância social e que objetive a consolidação da consciência ambiental. Para isso, necessita de um plano pedagógico, de vertente interdisciplinar e de múltiplas dimensões, que desenvolva no educando a sensibilidade crítica, reflexiva e ambiental.

\section{Referências}

ABRELPE. Panorama dos Resíduos Sólidos no Brasil. São Paulo: ABRELPE, 2017.

BRASIL. Ministério da Educação. Secretaria de Educação Básica. Diretrizes Curriculares Nacionais para a Educação Infantil. Secretaria de Educação Básica. Brasília: MEC-SEB, 2010.

BRASIL, Ministério da Educação e do Desporto. Secretaria de Educação Fundamental. Parâmetros Curriculares Nacionais: Ciências Naturais. Brasília: MEC/SEF, 1998. Disponível em:http://portal.mec.gov.br/seb/arquivos/pdf/ciencias.pdf.Acesso em: 03 set. 2018.

BRANDAO, Carlos Rodrigues; STRECK, Danilo Romeu (Org.). Pesquisa Participante: osaber da partilha. Aparecida/SP: Ideias \& Letras, 2006.p.295.

DELIZOICOV, Demétrio. Problemas e problematizações. In: Pietrocola, M. (Org.). Ensino de Física: conteúdo, metodologia e epistemologia em uma concepção integradora. Florianópolis: UFSC, 2005.p.25-150.

DELIZOICOV, Demétrio; ANGOTTI, JoséAndré. Metodologia do Ensino de Ciências. 2 ed. São Paulo: Cortez,1992.

DELIZOICOV, Demétrio; ANGOTTI, José André.; PERNAMBUCO, Marta Maria. Ensino de Ciências: fundamentos e métodos.4 ed. São Paulo: Cortez, 2011. p.366. 
DELIZOICOV, Demétrio; LORENZETTI, Leonir. Alfabetização científica no contexto das séries iniciais. Ensaio. v 3, nº1, jun. 2001. Disponível em:

http://www.portal.fae.ufmg.br/seer/index.php/ensaio/article/viewFile/35/66. Acesso em: 24 ago. 2018.

FRACALANZA, Hilário; AMARAL, Ivan Amorosino do; MEDIG NETO, Jorge; EBERLIN, ThaisSchiavinato. A Educação Ambiental no Brasil: Panorama Inicial de produção acadêmica.In: V Encontro Nacional de Pesquisa em Educação em Ciências. Associação Brasileira de Pesquisa em Educação em Ciências - Atas do V ENPEC- No 5, 2005.

FREIRE, Paulo. Pedagogia do Oprimido. 32. ed. Rio de Janeiro: Paz e Terra, 2002.

MOLL, Jaqueline.A cidade educadora como possibilidade - apontamentos. In: TOLEDO, Leslie; FLORES, Maria Rodrigues; CONZATTI, Marli (Orgs.). Cidade Educadora: a experiência de Porto Alegre. São Paulo: Cortez, Instituto Paulo Freire; Buenos Aires: Ciudades Educadoras, America Latina, 2004.

MORAN, José Manuel. Leituras dos Meios de Comnunicação. São Paulo: Pancast, 1993

PIAGET, Jean. Epistemologia Genética. São Paulo: Martins Fontes, 1990.

SECOVI. Guia para Destinação do Lixo Reciclável. Canindé/SP: SECOVI-Universidade SECOVI, 2013.

TREVISAN, Inês; FORSBERG, Maria Clara Silva. Aulas de campo no ensino de ciências e biologia: aproximações com a abordagem Ciência, Tecnologia e Sociedade (CTS). Scientia Amazonia, v. 3, n.1, 138-148, 2014. Disponível em: http://scientia-amazonia.org/wpcontent/uploads/2016/06/v3-n1-138-148-2014.pdf. Acesso em: 10 set. de2018. 